No. 5

Poverty measurement blues: Some reflections on the space for understanding 'chronic' and 'structural' poverty in South Africa Andries du Toit 


\section{Poverty measurement blues: Some reflections on the space for understanding 'chronic' and 'structural' poverty in South Africa}

by Andries du Toit (presence@iafrica.com)

Downloadable from www.uwc.ac.za/plaas

Andries du Toit is a Senior Researcher at the Programme for Land and Agrarian Studies (PLAAS) at the University of the Western Cape's School of Government and was formerly a Visiting Research Fellow in the Centre for Social Science Research at the University of Cape Town.

Programme for Land and Agrarian Studies (PLAAS), School of Government, University of the Western Cape, Private Bag X17, Bellville 7535, Cape Town, South Africa. Tel: +27 219593733. Fax: +27 21959 3732. plaas@uwc.ac.za. www.uwc.ac.za/plaas

Published by PLAAS in conjunction with the Chronic Poverty Research Centre (CPRC), Institute for Development Policy and Management, University of Manchester, and the Centre for Social Science Research, University of Cape Town.

PLAAS Chronic poverty and development policy series; no. 5.

Centre for Social Science Research, University of Cape Town working paper; no. 101.

Chronic Poverty Research Centre working paper; no. 49.

All rights reserved. No part of this publication may be reproduced or transmitted, in any form or by any means, without prior permission from the publisher or the author.

Copy-editor: Samia Singh

Layout: Designs for development

Map: John Hall 


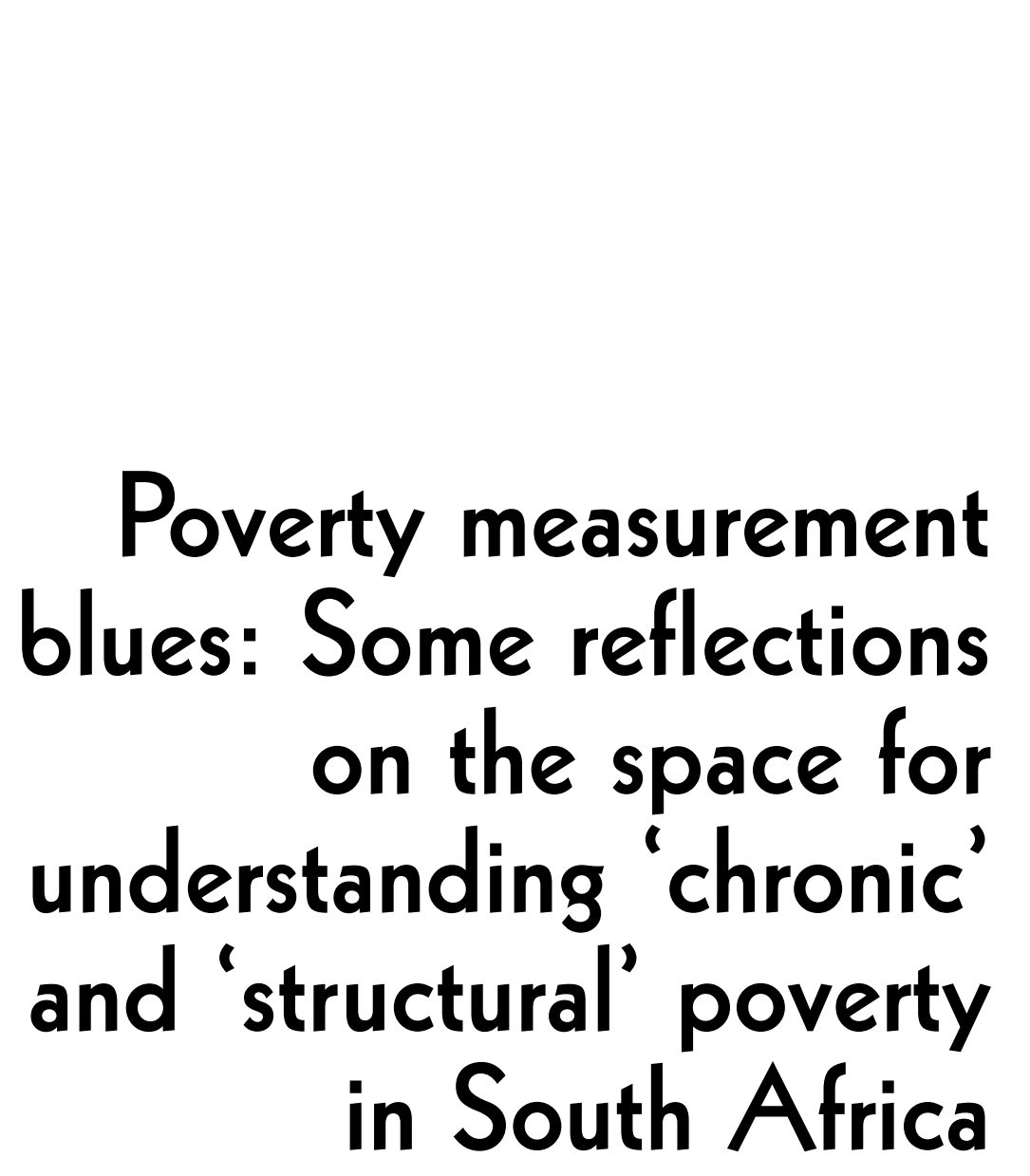

Chronic poverty and development policy No. 5

Andries du Toit

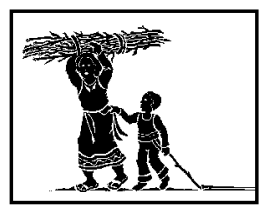

Programme for Land and Agrarian Studies July 2005 


\section{Contents}

Abstract

Author's note iii

1. Introduction 1

2. Imagining and understanding chronic poverty 2

Conceptualising and measuring chronic poverty 2

Some chronic problems with poverty measurement 2

Capabilities and multidimensionality 3

3. From chronic to structural poverty 6

Vulnerability, agency and structural poverty 6

From 'distributions' to relationships 6

4. Poverty measurement and the government of poverty 10

Beyond O-squared 10

Power, knowledge methodological dissent 11

5. Conclusion 13

$\begin{array}{ll}\text { References } & 14\end{array}$

\section{Figure}

Figure 1: PLAAS and CPRC's research sites in South Africa 7 


\section{Abstract}

This paper explores the challenge of understanding chronic and structural poverty in South Africa, and questions the dominance of the econometric imaginary in present-day development and poverty studies. It argues that measurement-based, econometric approaches to chronic poverty are dependent upon mystifying narratives about the nature of poverty and how it can be known, that they direct attention away from the underlying structural dimensions of persistent poverty and that understanding structural poverty in turn requires a theorised engagement with the complexities of social relations, agency, culture and subjectivity. Valuable as the recent re-recognition of the need to connect qualitative and quantitative research has been, attempts at 'qual-quant' integration often remain tied to positivist assumptions - bringing the risk of a new 'ordering' of methodological dissent that leaves problematic aspects of the econometric imaginary unchanged. Underlying this process is the entanglement of poverty research with the 'government of poverty': the attempt to constitute poverty as something objectively measurable and scientifically manageable. The paper closes with a consideration of the ethical and political challenges this poses for critical researchers and intellectuals in post-colonial contexts. 


\section{Author's note}

This paper is based on research funded by the Chronic Poverty Research Centre (see www.chronicpoverty.org). An earlier version was presented to the First International Conference on Qualitative Inquiry (see www.qi2005.org). It recapitulates and elaborates on arguments of an earlier, as yet unpublished paper (Du Toit 2005b) which was developed while a visiting researcher at the Centre for Social Science Research (CSSR), and which is available on request from the author. Many thanks to those who saw and commented on this early draft, including Philippa Bevan, Colleen Crawford Cousins, Uma Kothari and Jeremy Seekings.

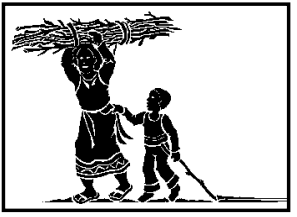





\section{Introduction}

We don't want complicated stories. What we need is a number. One number, if possible. One indicator that tells us where the poor and vulnerable are.

That's what we need. (Member of the Regional Vulnerability Assessment Committee for Botswana, at a planning meeting of the Southern African Vulnerability Initiative, October 2004).

Discussions about method and methodology in applied social research are often framed as if the central differences are those between quantitative and qualitative methods, and as if the key issue to be decided is the value of one or the other - or the best way of 'integrating' them (see Kanbur 2002). This paper argues that it is necessary to go further. It considers the difficulties that arise out of the domination of development studies and poverty research by what is here called the "econometric imaginary': an approach that frames questions of social understanding essentially as questions of measurement. Although the limitations of the econometric imaginary clearly illustrate the need for qualitative modes of research and understanding, I argue here that, although it is important to think about various methods of combining or 'integrating' qualitative and quantitative approaches, there is another, additional and more daunting challenge that cannot be avoided. Also pertinent is the larger explanatory meta-narratives: the paradigms and theoretical frameworks that guide the process of integration. Meeting this challenge is, however, impossible without an engagement with the ways in which applied social science research in the $21^{\text {st }}$ century is shaped by the architectures of power and knowledge in modern states and donor institutions. In South Africa, these limitations, I argue, are part of a fertile yet hazardous terrain for engagement and contestation by critical scholars and researchers.

These threads of argument are hung from the rather humble edifice of a consideration of some years of 'chronic poverty' research conducted in South Africa (see Aliber 2001; De Swardt 2004a, 2004b; Du Toit 2004, 2005a; Du Toit, Skuse \& Cousins 2005; Arnall et al. 2004) and the attempt to link the findings of this research to mainstream debates on chronic poverty. In the first place, the paper argues that dominant approaches to the conceptualisation of chronic poverty are undermined by their reliance on a mystificatory theoretical meta-narrative that tries to imbue poverty judgements with a spurious aura of objectivity and by the fact that they direct attention away from structural aspects of persistent poverty. Secondly, it argues that if the analysis of structural poverty is to avoid reductionism or abstraction, we need to come to grips with the extent to which the structural configurations of poverty are socially meaningful; shaped through and through by the complexities of culture, identity and agency. Thirdly, it proposes that this implies that more is needed than the simple addition of qualitative data to existing measurement-based accounts: instead, critical theory allows a re-imagining and reframing of the way in which inequality and poverty are conceptualised in the first place. The paper closes with a consideration of some of the obstacles and limitations to be faced in an attempt to bring these alternative ways of imagining poverty into the mainstream of applied poverty work in South Africa.

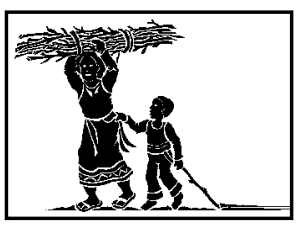




\section{Imagining and understanding chronic poverty}

\section{Conceptualising and measuring chronic poverty}

Our research on persistent poverty in South

Africa is essentially framed by the organising concept of chronic poverty. This is often given a fairly broad meaning - in the work of the Chronic Poverty Research Centre (CPRC), for instance, it refers inter alia to poverty of long duration, the poverty of those who are poor for most of their lives and 'transmit their poverty' [sic] to subsequent generations, to the situation of those caught in poverty traps and to those who number among the 'hard-to-reach poor', and so on (see Hulme \& Shepherd 2003; CPRC 2004). Ultimately, however, chronic poverty is usually understood, in its canonical econometric sense, in contradistinction to transitory poverty. Though the econometric analysis of chronic poverty is possible on the basis of 'static' indicators that are robust to change over time (for example, Chauduri \& Ravallion 1994; see also McKay \& Lawson 2003), a preferred strategy is to aggregate static snapshots in a way that might allow a composite 'moving' picture to emerge. A typical approach is to run a panel dataset and to use a poverty line (most commonly monetary in nature) to develop a dichotomous indicator which is then used to divide the individuals in the population in each wave of the panel study into two groups - usually 'the poor' and 'the non-poor'. Those who move above (or dip below) the poverty line are held to have 'escaped poverty' (or to have 'entered' it); those who are counted as poor in every wave of the survey, or who on average remain below the poverty line are counted as the "chronically poor' (see Bane \& Elwood 1986; Baulch 1996; Baulch \& Masset 2003). This approach dominates the ways in which 'the chronic poor' are identified; although other ways of approaching persistent poverty exist they are often treated simply as complementary.

In this paper I argue that, important as the distinction between chronic and transitory poverty can be, it is also very limited, focusing attention away from other matters critical to the understanding of persistent poverty. It is also tied up with some deeply problematic - indeed, thoroughly mystificatory - underlying metanarratives about poverty itself, what it is and how it can be scientifically known. To go beyond the limitations of the econometric concept of chronic poverty, then, it is necessary to engage with the ways in which the econometric imaginary dominant in applied social science frames the concept of poverty itself.

\section{Some chronic problems with poverty measurement}

Let us begin this engagement by considering the practices of 'poverty measurement' upon

which the definition of chronic poverty - and the identification of 'the chronic poor' - depend. These involve, as we have seen, two key operations. Firstly, they require the identification of an 'indicator' which stands as a proxy for the state of poverty; and secondly they involve the division of a 'population' into two groups on the basis of this indicator.

These operations involve three key difficulties. Firstly, poverty judgements - judgements as to whether someone is poor, and about what it is that constitutes their poverty - are ordinarily moral and political judgements: they derive their import and are invested with significance and consequence by virtue of being embedded in underlying discourses about the nature of society, the identity of its members, and the nature of the claims and counter-claims that membership enables. Furthermore, poverty judgements are always made by particular social actors, and are therefore always part of some larger social and political agenda. Any judgement about whether or not a particular person is poor - or about what the 'essentials of life' are, the lack of which constitutes poverty - is always a political judgement and is 
often contested (Noble, Ratcliffe \& Wright 2004). This means that there is no objective, uncontroversial, value-free and unitary concept of poverty directly available for transparent operationalisation by 'social science'.

Scholarly and applied research about poverty cannot disregard this. The claims poverty experts make to truth, resources, time and attention are dependent - even parasitic - upon these broader and essentially contested political and moral meta-narratives. Trying to impart a spurious cut-and-dried 'objective' 'scientificity' to poverty measurement is not to make it rigorous, but to mystify it.

This is not simply an abstract point. Consider the role played by poverty lines in the attempt to make poverty judgements rigorous and objective. As should be evident, this immediately raises the issue of just where the poverty line should be set. (For a South African discussion see Leibbrandt \& Woolard 2001.) Some have developed interesting approaches that attempt to ground this decision in local consensus(es) about 'socially accepted necessities' (Noble, Ratcliffe \& Wright 2004), but quite often this decision seems to be informed by the assumption that value judgements can be avoided altogether and that it is possible to develop a 'scientific' standard based on some 'objective' reality - for example dietary needs, caloric intake requirements and the like (see Baulch \& Masset 2003). Almost inevitably this leads not to an uncontroversial but to a punishingly conservative poverty line - one in which only those who are at risk of starvation or malnutrition will ever really formally count as poor - and a situation where, paradoxically, there is widespread poverty above the poverty line.

Secondly, one important consequence of the inherently political and moral character of poverty judgements is that they involve a wide space for nuance and indeterminacy. It is part of the logic of the concept of poverty that we can speak of someone as being, for example, 'not very poor', 'almost poor' or 'poor - for a white person'. The econometric habit of dividing 'populations' into 'poor' and 'non'poor - a distinction absolutely central to the way in which chronic poverty is distinguished from transitory - involves a misrecognition of this essential feature. Though some have attempted to recognise the space for indeterminacy in poverty judgements, for example, by using fuzzy set theory (Qizilbash
2002), these involve a doomed attempt to shoehorn them into a binary, two-tailed form.

Thirdly, poverty judgements are complex, theory-rich and layered interpretations, not simply of one aspect of a person or group's existence (how much they earn, for instance) but of complex and dynamic states of wellbeing or suffering. Though those 'states of being' typically involve aspects of deprivation, some of which may be quantifiable, these are moments in a complex non-linear interactive process - 'transient elements in the moving now,' as Bevan (2004:28) puts it - a process in which they figure both as momentary outcomes of complex interactions and as determinants of further interactions. What is central in understanding people's prospects and situations is not any particular aspect of deprivation but how all the facets of their existence and experience come together in a complex, and always historically situated, way to produce a state of lack, powerlessness or need which can then (always in a particular context and always by particular people) be called poverty.

Econometric definitions of poverty on the other hand are, as Bevan (2004) has pointed out, measurement-based, relying on the interpretation of 'indicators' which in turn are created through abstracting and isolating particular elements of people's overall situation from the broader context in which they exist and assigning meanings to them in their own right. This is a tricky enterprise, in which a lot depends on the ability to use those indicators in an informed way; and it is particularly dangerous in flagging a condition such as 'poverty', which is highly complex, comprising a number of different determinants, mechanisms and long term trajectories. In practice the definition of poverty is essentially collapsed into its indicator - and the indicator then taken for the condition it tries to measure: a circular operation that directs attention away from a concern with the complex underlying causal dynamics that link particular aspects of deprivation with the social experience of lack disempowerment, need and suffering.

\section{Capabilities and multidimensionality}

The problems pointed out here apply most trenchantly - and most obviously - to that most familiar of 'poverty indicators': income or expenditure measured at household level. 
One approach that attempts to transcend some of the limitations of this approach involves a focus, deriving from the work of Amartya Sen, on 'multidimensional' poverty and on people's 'capabilities'. Sen famously argued that the study of poverty should focus, not on attempting to measure income and expenditure, but on the underlying capabilities without which it is not possible to live a fully human life (Sen 1999; Nussbaum 1999). This offers the potential for an account of poverty that is alive to the complex and time-bound dynamics of deprivation, suffering and need. Although the capabilities approach has fundamentally challenged some of the underlying assumptions of welfare economics, its implications have only been followed through in limited ways. Sen's framework is notoriously hard to operationalise (see Chiappero-Martinetti 2000), and many attempts at operationalisation have fallen afoul of similar problems to those described in the previous section. Typically, attempts to put it into practice have involved identifying various capabilities (for example, health, nutrition, education, political participation), matching these to quantifiable indicators (longevity, anthropometric measurements, school enrolments, democratic institutions), and then trying to assess whether or not people are deprived according to these criteria (see UNDP 2002; Barrientos 2003; Klasen 2000; Qizilbash 2004; McGillivray 2003). This can shed valuable additional light on the extent and nature of poverty, making visible aspects of deprivation not discernable from an income perspective alone - but ultimately the underlying problem has not been transcended. McGillivray (2003), for instance, has endeavoured to use correlations between 'non-economic dimensions of wellbeing' (life expectancy, adult literacy, gross school enrolment) to empirically identify 'the variation not accounted for by income per capita', and then taking this variation as an 'aggregate measure of non-economic wellbeing' - assuming, in other words, that there is some abstract thing called 'non-economic well-being' which all these indicators partly measure. Another, less extreme example is again Baulch and Masset (2003), who understand the idea that 'monetary and nonmonetary indicators of poverty tell different stories about chronic poverty' to mean that there are 'different subgroups' of the chronic poor, or even different kinds of chronic poverty (for example 'nutritional poverty', 'chronic education poverty' - Baulch \& Masset 2003: 449-50).

Aside from the conceptual difficulties involved in describing capability deprivation in this way (how can hunger, for example, be described as 'non-economic'?) this approach produces intractable problems when used to try to identify 'the chronic poor' on the basis of panel studies. Are 'the chronic poor' only those who show up as deprived every time along every dimension measured? If we do not wish to adopt such a rigorous criterion, should we disaggregate 'the chronic poor' into 'the chronic monetary poor', 'the chronically malnourished', and so on? And how are we to understand the difference between those who are deprived in 'only one' dimension and those who suffer multiple forms of deprivation? (Is someone who is educationally deprived, chronically sick and food-insecure three times as poor as someone who is just food-insecure? Is someone who is deprived in two 'dimensions' as poor as someone who is deprived in two others?) These seem like silly questions, but they are precisely the ones that arise in any attempt to develop an aggregate multidimensional poverty score, or to rank poor people - activities that are routine in econometric approaches to poverty (see Atkinson 2003; Bourguignon \& Chakravarty 2003).

Surely all this misses Sen's point? The relationship between human capabilities and the 'full human life' that they enable is complex and dynamic. To treat the absence of a particular capability, or the lack of access to the resources required for it, as an 'indicator' of 'poverty' is to reify it and to miss its significance. Those who lack education are not suffering from 'education poverty'; and those who have poor health are not 'the health poor'. They are caught in a process of lack, deprivation or suffering which may or may not lead to a severe impairment of their agency and functioning in the world - and the different dimensions of their deprivation reflect the diverse material roots and determinants of that state. It may well be that those who are deprived in more dimensions than one are less likely to escape poverty - but this depends on the local structural context and the actual, empirical ways in which different aspects of 
deprivation play into and feed into one another. The significance of a variation, for example, in literacy or access to water lies not in the fact that they are 'indicators' or transparent reflections of 'non-economic well-being', but in their implications and consequences for what people can do - which are always shaped by a dynamic and complex interplay, and which are irreducibly different and therefore non-substitutable.

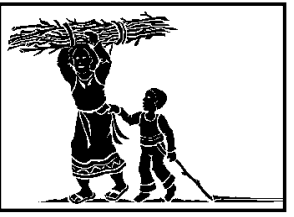




\section{From chronic to structural poverty}

\section{Vulnerability, agency and structural poverty}

If we want to identify 'the chronic poor' and understand what keeps them poor, measurement-based approaches, then, offer only a slippery grasp. A different approach is to recognise that many of those who show up as 'transitorily poor' in a panel study may still be held to be chronically poor if their underlying situation - the way they are structurally inserted in society - means that they are unlikely to get out of poverty in the long run. Such an approach requires an engagement with the causal dynamics and processes that drive and shape livelihood careers. Understanding who is likely to sink into poverty, who is likely to stay out of it for long periods of time, and who is able to make the investments required to ensure that a subsequent generation gets out (or stays out) of it requires not only the post-hoc tracking of actual welfare over time, but also an assessment of the underlying factors that shape their likely welfare. This means that the study of chronic poverty - and the identification of the chronically poor - is inseparable from the study of structural poverty and vulnerability.

Development economics and econometrics are not disciplines well geared towards understanding the structural configurations of vulnerability. Sen's approach and the presently popular 'livelihoods framework' at least orient enquiry towards an exploration of the material systems that underlie poverty and well-being - but even they offer scant guidance, partly because they offer abstract and decontextualised methods of thinking about the particular ways in which individuals and groups are situated in society.

Here, it may be instructive to look at one of the more innovative attempts in South African poverty scholarship to use econometric analysis to develop an assessment, not simply of whether or not people are poor, but of their underlying 'structural poverty': Carter and
May's (2001) analysis of the KwaZulu-Natal Income Dynamics Study panel dataset (see also Carter \& Barrett 2005). Their analysis goes well beyond the limitations explored above, partly because it uses a component analysis to explore the underlying aspects of people's livelihood situation. Rather than simply look at income, expenditure or capability-deprivation, Carter and Barrett look at the assets (land, human capital, financial wealth, social claims and grain stocks) upon which households rely to generate their income. They argue that households whose assets fall below the level required to generate an income equal to the poverty line are 'structurally poor' even though a windfall may cause them show up above the income poverty line during a particular measurement. They further postulate that though some people may suffer transitory structural poverty (in other words, 'structural poverty' from which is it possible to escape by accumulating sufficient assets) there may be a 'Micawber threshold' - a level of asset deprivation so severe it renders escape through accumulation impossible.

\section{From 'distributions' to relationships}

This is an important corrective to the "structure blindness' in definitions of chronic poverty that rely on poverty spells. It raises an important point - although the notion of 'the steady level of well-being' a household 'can expect' based on a particular level of assets or asset combination is a useful fiction, a fiction it to some extent remains. Any attempt to 'derive' an expected income level from an assessment of a given household's asset base will be dogged by uncertainty - particularly if we want to start including notions like 'social capital' in that asset base. Although there is a link between the assets over which someone disposes, and the income one may expect them to generate from it, the link is not linear and is mediated in complex ways by a host of other often non-quantifiable factors. 
This is something not well-recognised in the econometric approach to poverty and social understanding. For all the innovativeness of their approach, May, Carter and Barrett still see inequality statistically: as a matter of distribution. This is where the seductive language of 'household assets', 'social capital' and 'human capital' becomes dangerously misleading. For one thing, households are not natural units but small, open systems (Bevan, pers. comm.) that are internally contested, that change and re-form over time. A household's access to resources is powerfully mediated by networks and connections that extend outside the supposed household boundaries, so that there is often not a very clear line between household members and non-members (Russel 2004; Du Toit; Skuse \& Cousins 2005). For another, social capital is not a quantifiable resource, like a seed bank or a herd of cattle, which exists in greater or lesser amounts and which can be cashed or converted into other forms of capital in predictable ways. It is a general term for a wide range of variously structured human relationships - kinship networks, friendships, affiliation to formal and informal bodies, patron-client relationships and political alliances - that can be used to make claims and counter-claims (Du Toit, Skuse \& Cousins 2005). These, crucially, are meaningful relationships: deeply informed and shaped by underlying ideologies, moral metanarratives and cultural paradigms that come together to form a more or less consensual or contested 'moral economy' (Thompson 1964; Scott 1985) that defines them and specifies which expectations can legitimately be based upon them.

A consideration of the different social landscapes explored as part of PLAAS's ongoing poverty research in South Africa (see Figure 1) highlights how these complex webs of relationship and power work in very different ways in different contexts. On the commercial fruit farms of Ceres, for instance, one very important form of 'social capital' is constituted by the highly racialised patronclient relationships between the coloured workers who work on deciduous fruit farms and the white people who manage and own them (Du Toit 2004). These relationships are shaped by discourses and practices of paternalism that took shape in the course of a century-and-a-half of slavery and that

\section{Figure 1: PLAAS and CPRC's research sites in South Africa}
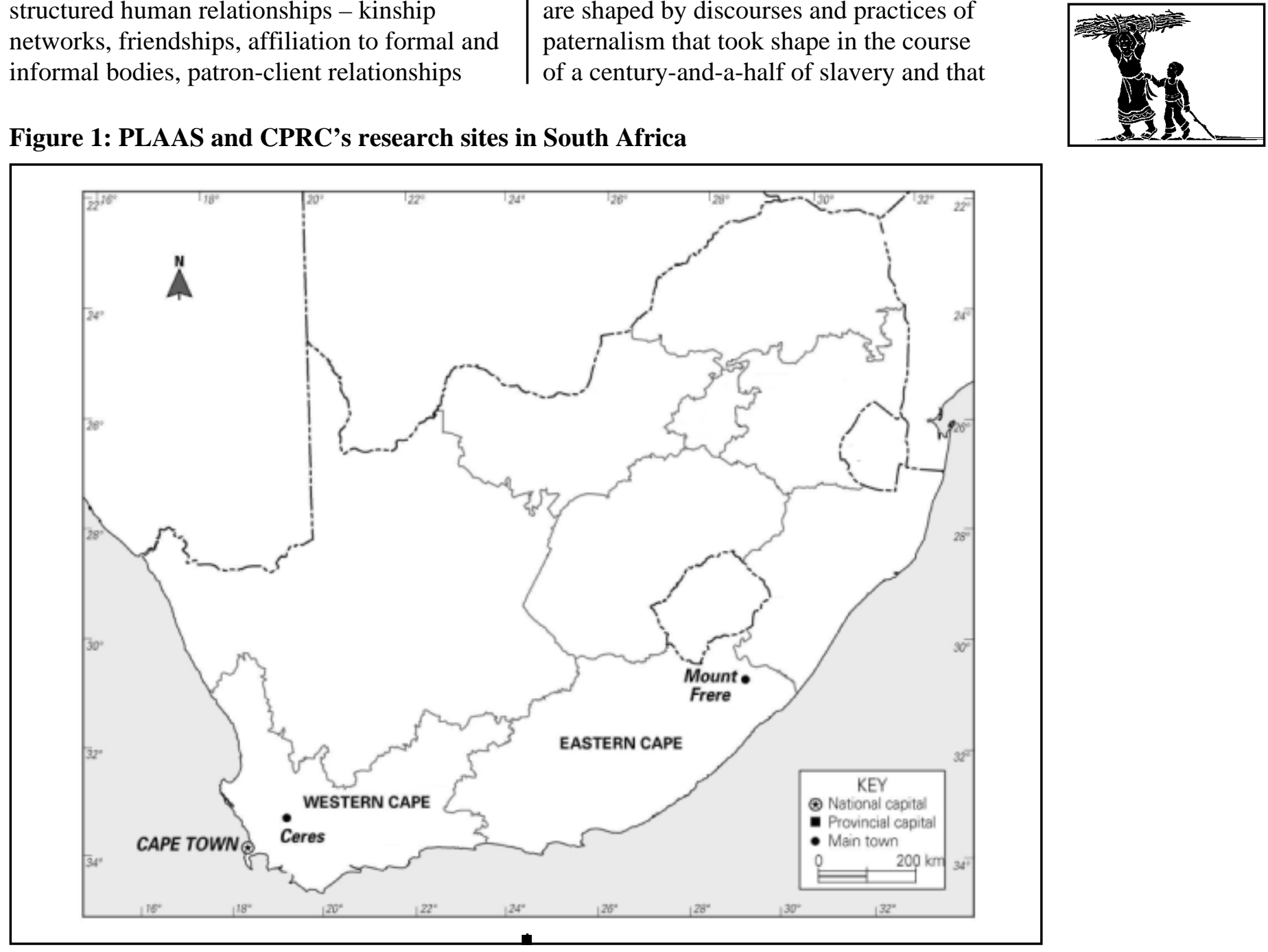


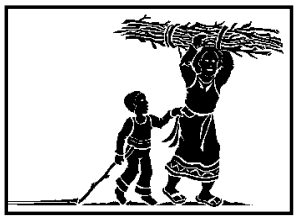

adapted and mutated into new forms in the course of a century-and-a-half more of capitalist modernisation (Du Toit 1993, 1998; Ewert \& Hamman 1999; Du Toit \& Ewert 2005). Paternalist discourse sets in place an underlying 'moral community' between black and white that is highly racialised and hierarchical, which also allows for the formulation of claims for resources and protection dependent on personal histories of loyalty and service; and which requires a complex politics of moral suasion, hidden resistance and subtle negotiation beneath a façade of racial deference. This racialised ideology shapes relationships among white and black, between African and coloured and among the powerful and the powerless even off the farms (Du Toit 2004). People with highly similar levels of 'asset endowment' as the livelihood framework (or Carter \& May 2001) would describe them, will have wildly different fortunes depending on their ability to negotiate these relationships and to secure their interests.

In Mount Frere in the remote Eastern Cape, 'social capital' is also central - but here what matters are complex traditional networks of kinship and patronage shaped by the history of the Eastern Cape and the ways in which these have adapted and mutated in response to modernisation and change (Skuse \& Cousins 2005a; Du Toit, Skuse \& Cousins 2005). Social capital is embedded and embodied by a vast, complex, relational economy involving domestic fluidity and 'stretched' households' (Spiegel, Watson \& Wilkinson 1999) extensive trade in goods, services, favours, labour and sometimes even money; and shaped by more than a century of migrant labour. The local cultures that shape this relational economy and define people's expectations about themselves and one another are thoroughly different from those one would find in Ceres: though Xhosa culture has not persisted unchanged into modernity, local traditions about identity gender and status, for instance, play a powerful role in shaping aspirations and behaviour. Again, households that look very similar in a livelihood survey can have very different fortunes depending on their links to local elites, their ability to make claims and to exploit sometimes tangential kinship networks.

In Cape Town's 'African' suburbs (De Swardt 2004b; Skuse \& Cousins 2005b) survival also depends on an informal relational economy, but here things work very differently again. Kinship is important, but it is only one of a wide range of social relations, affiliations, alliances and enmities that structure and are structured by informal exchange. Xhosa cultural forms and practices are still important, but the ethos is much less shaped by traditionalism and is infused with an assertive, street-smart urbanity (Skuse \& Cousins 2005b). What matters here is the ability to 'work' the urban system to get access to social services; the ability to juggle debts and obligations and the 'politics of intimacy' in the dance of the relational economy; the ability to manage risk and violence, and the ability to interface effectively with white society and the formal economy. The ability to insert oneself in complex local development processes; the ability to claim membership of particular subcommunities and interest groups; one's history of belonging in Khayelitsha and the alliances and allegiances thus formed all have a major impact on the resources one can mobilise.

In all three of these contexts, the local logic of social capital leads to the identification of very different groups of vulnerable people. In Mount Frere, for instance, women and girl children bear the brunt of the impact of gender roles that assign them most of the responsibility for household reproduction (Du Toit, Skuse \& Cousins 2005). At the same time, those gender roles have given them, after more than a century of migrant labour, a very real centrality in the networks of civil society, while young men are no longer as able to use migrancy as a path to full adult manhood. A different vulnerable group is comprised by older people who end up being the heads of HIV/Aids-affected households. In urban Cape Town, it is young women who are particularly at risk, partly because gender roles dictate that they should be dependent on men. In Ceres, African men and women are disadvantaged by local culture that constructs them as outsiders (Du Toit 2005b).

Clearly an attempt to deduce 'expected incomes' from 'asset combinations' by running regressions on household survey data stands a poor chance of uncovering any of this complexity. The point is not merely that there is plenty that does not show up on the radar of any particular dataset. It is also that the incorporation of these additional factors involves, not merely their addition to an existing analysis of correlations, but 
the development of a critical theoretical account of power, ideology, culture and inequality in these contexts. The thumbnail sketches provided above derive from an analysis informed by family of (Geertzian and Foucauldian; agent-centred and structuralist) theoretical frameworks very different from the econometric one - a theoretical imaginary that emphasises the role of structure, agency, antagonism and social change. According to these the perspectives and stated experiences of various social actors are not taken simply at face value but seen as complex social creations, shaped by social power relations and in turn impacting upon them. This has crucial implications for the prospects of building more robust accounts of the nature of structural and chronic poverty. 


\section{Poverty measurement and the government of poverty}

\section{Beyond Q-squared}

In one sense, of course, none of the above arguments are very new. Arguments about the limitations of purely quantitative research are probably as old as 'quantitative social science' itself and have recently become commonplace again even within the development mainstream (see Kanbur 2002). This recognition has, however, usually taken quite a limited form - being confined, for instance, to the idea that it is enough for 'quantitative approaches' to be supplemented, corrected or added to in some way by 'qualitative' research. This is undoubtedly a good thing: forays into 'qsquared', attempts to integrate qualitative and quantitative work, clearly adds to the rigour, depth, reach and accuracy of poverty research (see Adato, Lund \& Mhlongo 2004). At the same time, this recognition is often quite circumspect and the integration between 'qualitative' and 'quantitative' often takes place in restricted ways. For writers like Thorbecke, for instance, qualitative data seems to be understood as being equivalent to doing some PRAs (participatory rural appraisals) - and the role of qualitative data seems to be limited to generating hypotheses that can be quantitatively tested (Thorbecke 2004). Others admit of a wider range of methods and highlight a number of different ways in which qualitative and quantitative work can illustrate, confirm, refute, enrich and illuminate one another (Carvalho \& White 1997; see also Howe \& McKay 2004; Adato, Lund \& Mhlongo 2004). On the whole, however, 'qualitative data' has been seen to have an essentially supplementary and illustrative role in accounts of poverty still essentially shaped by the econometric imaginary. Even more problematically, 'qualitative data' itself is almost universally understood, very simplistically, as if it is transparently meaningful in itself. It is as if what emerges from PRAs, life histories, focus groups and the like can be taken at face value, without an engagement with the need to interpret these as textual artefacts, themselves the products of conflicts, antagonisms and other encounters that are shaped by social power relations and concrete social interests. There is, furthermore, very little reflexive awareness of the process of research itself and how this shapes the way 'qualitative data' is produced, analysed and interpreted.

There is a danger, therefore, that attempts to assert the value of qualitative research can simply take us back to a new positivism, in which slightly more methodologically diverse research strategies (household surveys plus focus group interviews; panel data sets plus life histories; econometric regressions plus PRAs) figure within accounts of society and social change - essentially still caught within the ahistorical, power-blind, technicist and rationalchoice imaginary of econometric analysis and mainstream development economics (see Kothari 2001). What the calls for 'integration' ignore is that the real issue is not whether we need to connect qualitative and quantitative research - we obviously do - but that any attempt at integration is always theory-rich, utterly dependent on underlying narratives about the nature of society, agency, power, poverty and social change.

Two issues arise out of this observation. The first is that this need not be so. If the purpose is indeed to understand chronic (and therefore structural) poverty, and to understand how social relations shape people's chances of getting into or out of poverty, the field of social science and critical social theory offers wide and deep resources. A veritable academic industry exists in which the links between power, agency, culture, identity and history are explored and which offers wide space for reflective and incisive accounts of the ways in which these are linked to the distribution of resources in society.

The second is that, in spite of this promise these critical traditions are to a large extent marginalised in the field of applied 
development and poverty studies, relegated to a fairly well-defined circuit of institutions and journals which development economists and poverty scholars seem to feel they can safely ignore. In South Africa, for instance, there is a rich legacy of critical debate and research dating from the 1980s and 1990s on the relationships between capital accumulation, identity, ideology, social change and inequality - a legacy that has been radicalised and extended more recently, in the work of institutions such as WISER (Wits Institute for Social and Economic research), into searching reflections on postcoloniality, racism and identity. At the same time it is possible for scholars (who, to all intents and purposes, are clearly deeply committed to social justice and the eradication of inequality and poverty) to produce an account of labour market vulnerability and poverty in South Africa ignores the 'revisionist' debates of the 1980s the criticism of liberal orthodoxy of the 1960s and 1970s (Bhorat et al. 2001; for a discussion see Du Toit 2005a).

\section{Power, knowledge and methodological dissent}

What is the scope for this state of affairs to be challenged and for applied social science in general (and policy-oriented poverty research in particular) to become more sensitive to the need for - and the power of - critical and agent-centred accounts of structural poverty and the prospects for getting out of it? In my own recent work (see Du Toit 2005a), I have, to some extent, attempted to name and problematise the marginalisation I have described here, which is all too often seen as the natural order of things.

One of the most prominent stated reasons for the failure of critical social theory to seriously challenge the hegemony of the econometric imaginary is that there is no clearly hegemonic 'critical theory' approach. In contrast to the field of economics and econometrics, where debates and discussions are underpinned by a widely shared and hegemonic framework setting the boundaries of a generally accepted 'normal science' (and also, in contrast, to the field of development studies, which lacks its own rigour but is thoroughly governed by the changing orthodoxies and frameworks adopted by leading donor institutions), critical social theory and anthropology has since the mid1980 s been characterised by a flowering of increasingly different and sometimes competing explanatory paradigms and ontologies, sub-disciplines and specialities (postcolonial, gender and cultural studies, social constructionism, critical realism, poststructuralist theory and discourse analysis, actor network theory, agent-centred theories, global value chain analysis, convention theory, to name but a few), with no particular approach succeeding in establishing itself as central or dominant. Norman Long has argued that, rather than being seen as fragmentation and crisis, this diversity should be recognised as a fundamental condition of social enquiry; and welcomed as an opportunity for innovation (Long 1992). Nevertheless, this diversity means that there is no single generally accepted 'qualitative' or 'non-positivist' or 'postfoundational' approach. Calls by economists for examples of generally accepted ways in which social theory can help us understand chronic poverty have to be met by the answer that there is no master paradigm. Any attempt to 'operationalise' the insights of qualitative sociology and critical social theory has to be partial and local, and will require the case-bycase theoretical concepts and approaches that can help illuminate particular problems.

This is, of course, only part of the story, the demand for 'normal science' in social research - for powerful, uncontroversial and replicable methodologies and schemas that can be used to produce reliable, policyrelevant knowledge about poverty - has its own political economy. Paradoxically, many of the most problematic features of poverty measurement described in previous pages are precisely those that make it attractive to governments and donor institutions. Some of the crucial operations I have criticised above arise to some extent out of the underlying logic of the social technologies of knowledge and power which make poverty measurement necessary and possible as an enterprise in the first place. Poverty measurement has a complex history, but a very important role in this history has been played by what we might call the historical project of the 'government of poverty'. The need for universal measurements and easily replicable indicators is indissolubly linked to the project of constituting poverty as an object of management and government - as something whose presence in society needs to

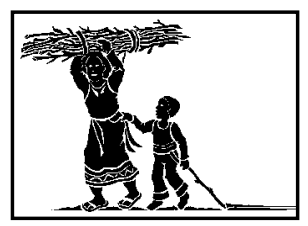


be recognised in ways that render it subject to regulation; and which can contain and limit its present as a radically disruptive political problematic.

As such, the discipline of poverty measurement is caught on the horns of a dilemma or a double bind: like the 'optics' of modern government identified by James C Scott (Scott 1998; but see also Foucault 1987), it is partly driven by the need to make society 'legible' in a regular, homogenous and universalising way. In order to be useful for the process of government and planning at all, technologies of measurement and assessment have to be developed that can be treated as independent, or which can be delinked from the complexity and non-transparency of local context. Economies of scale in government judgement and assessment require the development of embodied techniques of regularised knowing and decision-making. It should be possible to 'port' such techniques from one context to another so that one individual (or household or region) can be compared with another and ranked so that good decisions can be made about the allocation of resources. Such tools make it possible for operations to be done in the shadow of the authority of 'science' - apparently free of bias, objective and incontrovertible.

The problem, as Scott points out, arises when this process of abstraction and decontextualisation leads not to legibility but to misreading. When, for example, imposing the template of monoculture on forestry management destroys the underlying ecological base of biodiversity on which the forest depends, or when dirigiste city planners misunderstand the local dynamics that make neighbourhoods viable. In such cases the preference for certain kinds of information - information that is readily quantifiable and standardised, that abstracts from local complexity and appears to sidestep nontransparency - leads not to an accurate grasp of the dynamics of a situation, but to distorted and misleading accounts that miss crucial dynamics.

The question is what follows from the recognition of these distortions and misunderstandings. What scope is there for what Scott called metís - for forms of knowledge that allow for an understanding of some of these complex dynamics and which are by their very nature more provisional, more embodied and localised, more connected with specific histories and relationships, more value laden and political? What scope is there for the state to learn other ways of seeing and imagining poverty and vulnerability?

The struggle is an uphill one, if recent attempts to build governmental capacity to understand food insecurity and vulnerability in South Africa are anything to go by. A case study of the development of a Food Insecurity and Vulnerability Information and Mapping System (FIVIMS) for the 'social cluster' of departments in South Africa shows that, in spite of the recognition of the role of local history and power relations - and in spite of the acknowledgement of the importance of practical local knowledge embedded in institutions on the ground - very little could be done to shift the perception on the part of the officials involved that ultimately, what was practical was a geographical information systems (GIS)-based system that would provide information about 'indicators' of 'structural vulnerability' in unambiguous, map-able, quantifiable terms. (It is hoped that this experience will be explored in a separate case study - Du Toit, Vogel and Ziervogel; forthcoming.) This institutional inertia seemed to be produced partly by what one could call the mystique of 'quantitative data' - a wholly misplaced faith in what one could learn from the 'quantitative data' that is available for use in a GIS-based system - but partly also by underlying totalising narratives about the place of 'integrated planning and implementation' and centralised knowledge in the exercise of state power (Du Toit, Vogel \& Drimie 2005). Asking governments and donor institutions to make space for critical accounts of social change - accounts that are more sensitive to the nature and dynamics of power relations - seem inevitably to come up against the limitations that arise out of the present-day logic of forms of power-knowledge and modes of governmentality that seek to de-link claims to authority from knowledge from locality; and that depend on spatialised technologies for decontextualising and homogenising social and political space (for a broader discussion see Kothari 2005; Duffield 2004 \& 2005). 


\section{Conclusion}

What, then, is the scope for 'decolonising' methodologies that are so clearly linked to formations of power and knowledge so deeply shaped by their links to post-colonial and still-imperial forms of governance and governmentality? In the long run, there is only one way of finding out: by actually trying to contest homogenising quantitative narratives by developing powerful and convincing counter-hegemonic accounts. In South Africa, at least, it is possible to imagine that the terms of this engagement do not run only one way. Rather than being the stage for a seamless 'ordering of dissent' in which the institutions of globalised corporate power are always and inevitably able to contain criticism by incorporating it, the field of applied social science research in South Africa seem to embody a fruitful, if hazardous terrain for engagement. Given the urgency of addressing persistent poverty in South Africa and the dawning recognition by the ruling party that modernising narratives about 'trickle-down' are not working (Mbeki 2003), there is a wide scope for critical scholars to interrupt and to problematise the apparent self-evidence of normalising meta-narratives about growth, modernity, security and the like. It is part of both the fertility and the hazard of this terrain that all such interventions needs must be themselves situated and informed by an awareness of their own dependency on and inevitable complicity with a history steeped in conflict and suffering. 


\section{References}

Adato, M, Lund, F \& Mhlongo, P. 2004. Methodological innovations in research on the dynamics of poverty: A mixed method longitudinal study in KwaZuluNatal, South Africa. Paper presented at Q-squared in practice: A conference on experiences of combining qualitative and quantitative methods in poverty appraisal. http://www.utoronto.ca/mcis/q2/papers/IV_ Adato_Lund_Mhlongo.pdf

Aliber, M. 2001. Study of the incidence and nature of chronic poverty and development policy in South Africa: An overview. Manchester: Chronic Poverty Research Centre. (CPRC working paper; no.3.) www.chronicpoverty.org/pdfs/sa.pdf

Arnall, A, Furtado, J, Ghazoul, J \& De Swardt, C. 2004. Perceptions of informal safety nets: A case study from a South African informal settlement. Development Southern Africa, 21(3): 443-60.

Atkinson, AB. 2003. Multidimensional deprivation: Contrasting social welfare and counting approaches. Journal of Economic Inequality, 1:51-65.

Bane, MJ \& Ellwood, DT. 1986. Slipping into and out of poverty: The dynamics of spells. Journal of Human Resources, 21(1):1-23.

Barrientos, A. 2003. Non-contributory pensions and the well-being of older people: Evidence on multi-dimensional deprivation from Brazil and South Africa. Mimeo. Manchester: Institute for Development Policy and Management, University of Manchester.

Baulch, B. 1996. Neglected trade-offs in poverty measurement. IDS Bulletin, 27(1): $36-42$.

Baulch, B \& McCulloch, N. 1998. Being poor and becoming poor: Poverty status and poverty transitions in rural Pakistan. Brighton: Institute for Development Studies, University of Sussex. (IDS working paper; no. 79.)

Baulch, B \& Masset, E. 2003. Do monetary and non-monetary indicators tell the same story about chronic poverty? A study of Vietnam in the 1990s. World Development, 31(3):441-54.

Bevan, P. 2004. Exploring the structured dynamics of chronic poverty: A sociological approach. Bath: Wellbeing in Developing Countries ESRC research group, University of Bath. (WeD working paper; no. 06.) www.welldev.org.uk/research/ working.htm\#wed6

Bhorat, H, Leibbrandt, M, Maziya, M, Van der Bergh, S \& Woolard, I (eds). 2001. Fighting poverty: Labour markets and inequality in South Africa. Cape Town: University of Cape Town Press.

Bourguignon, F \& Chakravarty SR. 2003. The measurement of multidimensional poverty. Journal of Economic Inequality, 1:25-49.

Carter M, \& May, J. 2001. One kind of freedom: Poverty dynamics in post-apartheid South Africa. World Development, 29(12):1987-2006.

Carter, M \& Barret, C. 2005. The economics of poverty traps and persistent poverty: An asset-based approach. Ithaca: Cornell University. (Cornell Food and Nutrition Policy Programme working paper; no. 178.) www.cfnpp.cornell.edu/images/wp178.pdf

Carvalho, S \& White, H. 1997. Combining the quantitative and qualitative approaches to poverty measurement and analysis: The practice and the potential. Washington, DC: World Bank. (World Bank technical paper; no. 366.) www.wds.worldbank.org/servlet/ WDS_IBank_Servlet?pcont=details\&eid $=0$ 00009265_3971031092544

Chaudhuri, S \& Ravallion, M. 1994. How well do static indicators identify the chronically poor? Journal of Public Economics, 53: 367-94.

Chiappero-Martinetti, E. 2000.

A multidimensional assessment of wellbeing based on Sen's functioning approach. Revista Internazionale di Scienza Soziale, 108(2):207-39. 
Cichello, PL, Fields, GS \& Leibbrandt, M. 2003. Earnings and employment dynamics for Africans in post-apartheid South Africa: A panel study of KwaZuluNatal. Cape Town: Development Policy Research Unit. (DPRU working paper; no. 03/77.) www.commerce.uct.ac.za/dpru/ WorkingPapers/wp.asp?WP_ID=2003/77

CPRC (Chronic Poverty Research Centre). 2004. The chronic poverty report 2004-05. Manchester: CPRC. www.chronicpoverty.org/

De Swardt, C. 2004a. Chronic poverty and the basic income grant. Cape Town: Programme for Land and Agrarian Studies, University of the Western Cape. (Chronic poverty and development policy working paper; no. 2.) www.uwc.ac.za/plaas/ publications/poverty.htm

De Swardt, C. 2004b. Cape Town's African poor. Cape Town: Programme for Land and African Studies, University of the Western Cape. (Chronic poverty and development policy working paper; no.3.) www.uwc.ac.za/plaas/publications/ poverty.htm

Du Toit, A. 1993. The micropolitics of paternalism: Discourses of management and resistance on Western Cape fruit and wine farms. Journal of Southern African Studies, 19(3):314-36.

Du Toit, A. 1998. The fruits of modernity: Law, power and paternalism in Western Cape fruit and wine farms, in South Africa in transition: New theoretical perspectives, edited by A Norval and D Howarth. London: Macmillan:149-64.

Du Toit, A. 2004. Forgotten by the highway: globalization and chronic poverty in Ceres. Cape Town: Programme for Land and Agrarian Studies, University of the Western Cape, Centre for Social Science Research, University of Cape Town and Chronic Poverty Research Centre. www.chronicpoverty.org/pdfs/ 49\%20duToit.pdf

Du Toit, A. 2005a. Chronic and structural poverty in South Africa: Challenges for action and research. Cape Town: Programme for Land and Agrarian Studies, University of the Western Cape. (Chronic poverty and development policy series; no. 6.)
Du Toit, A. 2005b. Beyond Q-squared: Using qualitative and quantitative approaches to understand structural and chronic poverty in South Africa. Unpublished typescript.

Du Toit, A \& Ewert J. 2005. A deepening divide in the countryside: Restructuring and rural livelihoods in the South African wine industry. Journal of Southern African Studies, 31(2):315-32.

Du Toit, A, Skuse A \& Cousins, C. 2005. The political economy of social capital: Chronic poverty, remoteness and gender in the rural Eastern Cape. Unpublished typescript; Adelaide and Cape Town.

Du Toit, A, Vogel, C \& Drimie, S. 2005. Institutional arrangements and utilization of FIVIMS-ZA. Unpublished typescript.

Du Toit, A, Vogel, C \& Ziervogel, C. 2005. Maps in the dark: Bio-power, 'vulnerability' and the crisis of integrated planning. (Forthcoming, provisional title)

Duffield, M. 2004. Carry on killing: Global governance, humanitarianism and terror. DIIS Working Paper 2004/23, Copenhagen: Danish Institute for International Studies. www.diis.dk/graphics/Publications/ WP2004/duffield_carry_on_killing.pdf

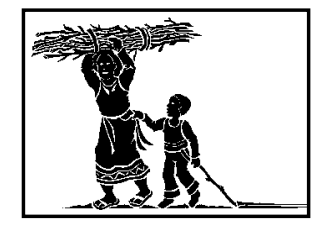

Duffield, M. 2005. Getting savages to fight barbarians: Development, security and the colonial present. Conflict, Security and Development, 5(2). (Forthcoming)

Ewert, J \& Hamman, J. 1999. Why paternalism survives: Globalisation, democratisation and labour on South African wine farms. Sociologia Ruralis, 39(2):202-21.

Foucault, M. 1987 [1977]. Discipline and punish: The birth of the prison. Harmondsworth: Penguin.

Howe, G \& McKay, A. 2004. Combining quantitative and qualitative methods in assessing chronic poverty: The case of $R$ wanda. Paper presented at 'Q-Squared in Practice: A Conference on Experiences of Combining Qualitative and Quantitative Methods in Poverty Appraisal', University of Toronto, 15-16 May. www.utoronto.ca/ mcis/q2/papers/VI_Mckay_Howe.pdf

Hulme, D \& Shepherd, A. 2003. Conceptualizing chronic poverty. World Development, 31(3):403-24. 
Kanbur, R. 2002. Economics, social science and development. World Development, 30(3):477-86.

Klasen, S. 2000. Measuring poverty and deprivation in South Africa. Review of Income and Wealth, 46(1):33-58.

Kothari, U. 2001. Power, knowledge and social control in participatory development, in Participation: The new tyranny, edited by B Cooke and U Kothari. London: Zed.

Kothari, U. 2005. Authority and expertise: The professionalisation of international development and the ordering of dissent. Antipode, 37(3):425-46.

Kritzinger, A \& Barrientos, SW. 2004. Squaring the circle: Global production and the informalization of work in South African fruit exports. Journal of International Development, 16:81-92.

Leibbrandt, M \& Woolard, I. 2001. Measuring poverty in South Africa, in Fighting poverty: Labour markets and inequality in South Africa, edited by H Bhorat, $\mathrm{M}$ Leibbrandt, M Maziya, S van der Bergh and I Woolard. Cape Town: University of Cape Town Press.

Long, N. 1992. From paradigm lost to paradigm regained: The case for an actor oriented sociology of development, in Battlefields of knowledge: The interlocking of theory and research in social theory and development, edited by $\mathrm{N}$ Long and A Long. Wageningen: Wageningen Agricultural University:17-42.

Mbeki, T. 2003. Letter from the President. www.anc.org.za/ancdocs/anctoday/2003/ at33.htm\#preslet

McCulloch, N \& Baulch, B. 1999. Distinguishing the chronically from the transitorily poor: Evidence from Pakistan. Brighton: Institute of Development Studies, University of Sussex. (IDS working paper; no. 97.) www.ids.ac.uk/ids/bookshop/wp/ wp97.pdf

McGillivray, M. 2003. Capturing noneconomic dimensions of human well-being. Paper presented at the World Institute for Development Economics Research Conference on Inequality, Poverty and Human Well-Being, Helsinki, 30-31 May. www.wider.unu.edu/conference/conference2003-2/conference\%202003-2-papers/ papers-pdf/McGillivray\%20280503.pdf

McKay, A \& Lawson, D. 2003. Assessing the extent and nature of chronic poverty in low income countries: Issues and evidence. World Development, 31(3):425-40.

Noble, M, Ratcliffe, A \& Wright, G. 2004. Conceptualising, defining and measuring poverty in South Africa: An argument for a consensual approach. Oxford: Centre for the Analysis of South African Social Policy, University of Oxford.

Nussbaum, M. 1999. Women and equality: The capabilities approach. International Labour Review, 138(3):227-45.

PASS (Programme of Advisory and Support Services to DFID). 2003. Review of the VAC methodology for assessing food needs. www.passlivelihoods.org.uk/ default.asp?project_id=77

Qizilbash, M. 2002. A note on the measurement of poverty and vulnerability in the South African context. Journal of International Development, 14:757-72.

Qizilbash, M. 2004. On the arbitrariness and robustness of multi-dimensional poverty rankings. Journal of Human Development, 5(3):355-75.

Ravallion, M. 1996. Issues in measuring and modelling poverty. The Economic Journal, 106:1328-43.

Russel, M. 2004. Understanding black households in southern Africa: The African kinship and Western nuclear family systems. Cape Town: Centre for Social Science Research, University of Cape Town. (CSSR working paper; no. 67.) www.cssr.uct.ac.za/ papers/wp67.zip

Scott, JC. 1985. Weapons of the weak: Everyday forms of peasant resistance. New Haven: Yale University Press.

Scott, JC. 1998. Seeing like a state: How certain schemes to improve the human condition have failed. New Haven: Yale University Press.

Sen, A. 1999. Development as freedom. Oxford: Oxford University Press.

Skuse, A \& Cousins, T. 2005a. Managing distance: The social dynamics of rural 
telecommunications access and use in the Eastern Cape, South Africa. Unpublished typescript submitted to Journal of African and Asian Studies (under review).

Skuse, A \& Cousins, T. 2005b. Getting connected: The social dynamics of urban telecommunications use in Khayelitsha, Cape Town. Unpublished typescript submitted to New Media and Society (under review).

Spiegel, A, Watson, V \& Wilkinson, P. 1999. Speaking truth to power: Some problems using ethnographic methods to influence the formulation of housing policy in South Africa, in The anthropology of power:

Empowerment and disempowerment in changing structure, edited by A Cheater. London and New York: Routledge:175-90.

Thompson, EP. 1964. The making of the English working class. Harmondsworth: Penguin.

Thorbecke, E. 2004. Conceptual and measurement issues in poverty analysis. Helsinki: World Institute for Development Economics Research. (WIDER discussion paper; no. 2004-004.) www.wider.unu.edu/ publications/dps/dps2004/dp2004-004.pdf

UNDP (United Nations Development Programme). 2002. Human development report 2002. New York: Oxford University Press. http://hdr.undp.org/reports/global/ 2002/en/ 